\title{
結核管理의 問題點
}

\section{一第33次 結核學術大會 講演內容一}

結協・結核研 究院

\author{
宋達鎬

\section{Problems on Tuberculosis Control in Korea} \\ Dal Ho Song, M. D. \\ Korean Institute of Tuberculosis, KNTA
}

오늘 우리나라 結核管理의 問題點을 論하게 된데 對 하여 삿은 세가지 重要한 뜻이 있다고 生覺합니다.

그 첫째는 今年이 우리나라 結核事業의 始初라고 할 수 있는 集團 $\mathrm{BCG}$ 接種을 始作한지 20年이 됩니다.

둘째로 今年에 처음으로 우리나라에서 結核에 關한 國際會議(第二次 WHO 西太平洋地域 結核管理卅미나) 가 開催되었읍니다.

끝으로 우리나라에서 처음으로 今年에 全國的인 結核 發病率調查(Incidence survey)가 貝施되었읍니다.

그리니까 우리나라 結核事業도 成年에 到達한 셈이고 國際的으로도 알려졌으며 基礎的인 疫學에 關한 情報도 收集되었으니 이제 좀더 强力하고 理論的인 結核事業을 이루기 爲하여 다시한번 偯重히 檢討할 時期가 아닌가 生覺합니다.

\section{I . 結核의 疫學的 實態}

그러면 먼저 結核實態에 關해서 지난번 WHO Seminar 에 參席했던 各國代表들로부터 얻은 情報와 우리나라 實 態調査結喿를 比較해서 말씀드리고 報告 兼해서 會議의 重要討議內容을 말씀드린 다음 그동안 이루어진 우리나 라 結核事業을 評價하기 爲하여 咋年度 全國事業에 關 한 分折과 問題點을 瑅示하겠읍니다.

\section{1. 結核死亡率(表 1 )}

東南亞各國은 아직도 結核이 十大死因中에 하나로 남

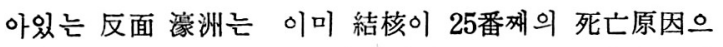
로 나타나 있으며 日本도 머지않아 十大死因中에서 벗어 날 것입니다. 우리나라의 境遇 1967 年 서울 市內에서 調

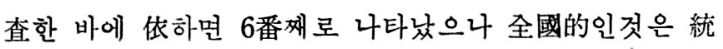
計發表가 없고 다만 結核協會 結核砰究院이 調查한 長
Table 1. Tuberculosis death(1967)

\begin{tabular}{l|r|r|r}
\hline \multicolumn{1}{c|}{ Country } & per 100,000 & $\begin{array}{r}\% \text { to } \\
\text { total } \\
\text { death }\end{array}$ & $\begin{array}{r}\text { Order in } \\
\text { cause of } \\
\text { death }\end{array}$ \\
\hline Philippines & \multicolumn{1}{|c|}{82.5} & 11.8 & 2 \\
Korea(Seoul) & 39.5 & 8.9 & 6 \\
(Whole country) & $(79.0)$ & $(14.7)$ & $?$ \\
Hongkong & $38.9(35.1)$ & 7.6 & 5 \\
China(Taiwan) & $36.2(28.1)$ & 6.9 & 5 \\
Singapore & $28.2(20.8)$ & 5.2 & 6 \\
Japan & $17.8(16.1)$ & 2.6 & 8 \\
New Zealand & 2.9 & 0.3 & 20 \\
Australia & $2.3(1.7)$ & 0.3 & 25 \\
\hline ( ) 1969 or 1970
\end{tabular}

Table 2. Tuberculosis prevalence rate

\begin{tabular}{l|c|c|c|c}
\hline Country & $\begin{array}{c}\text { Observed } \\
\text { in }\end{array}$ & $\begin{array}{c}\text { Age } \\
\text { group }\end{array}$ & $\begin{array}{c}\% \text { Xray } \\
\text { suspects }\end{array}$ & $\begin{array}{c}\% \\
\text { Bact. } \\
\text { conformed }\end{array}$ \\
\hline Korea & 1970 & $>5$ & 4.2 & 0.74 \\
Japan & $\begin{array}{c}1968 \\
(1953)\end{array}$ & $>5$ & $\begin{array}{c}1.5 \\
(3.4)\end{array}$ & $\begin{array}{c}0.09 \\
(0.75)\end{array}$ \\
China & 1968 & $>10$ & 2.8 & 0.50 \\
Malaysia & 1970 & $>15$ & $?$ & 0.57 \\
Laos & 1957 & $>15$ & 3.6 & 0.25 \\
Philippines & 1964 & $>5$ & 4.0 & 0.72 \\
Vietnam & 1962 & $>10$ & 10.4 & 0.91 \\
\hline
\end{tabular}


결핵 및 호흡기질환:Vol. 19, No. 1, Jan., 1972

期疫學調查에 依하면 人口十萬名當 79名으로 나타나 （1970年）年間 䄪 20,000名이 結核으로 死亡될것으로 推算됩니다.

\section{2. 結核有病率(表 2)}

東南亞 七個國中 結核有病率이 가장 낮은 나라는 日 本으로 X線上活動性結核이 人믜 $1.5 \%$ 이며 菌陽性患 者는 $0.09 \%$ 인가 하면 가장 높은나라는 越南으로 $\mathrm{X}$ 線 上活動幽結核 有病率이 $10.4 \%$ 에 菌陽性率은 $0.91 \%$ 입

Table 3. Prevalence of bacteriological positive cases in several countries.

\begin{tabular}{|c|c|c|c|c|}
\hline & $\begin{array}{l}1968 \\
\text { Japan }\end{array}$ & $\begin{array}{c}1967 \\
\text { China }\end{array}$ & $\begin{array}{c}1970 \\
\text { Korea }\end{array}$ & $\begin{array}{c}1970 \\
\text { Malaysia }\end{array}$ \\
\hline $0-4$ & & & & \\
\hline $5-9$ & & & & \\
\hline $10-$ & 0.02 & & 0.13 & \\
\hline $15-$ & 0.04 & & & \\
\hline 20 & 0.02 & $0 ?$ & & 0.03 \\
\hline $25-$ & 0.17 & & 0.73 & \\
\hline $30-$ & 0.20 & & & \\
\hline $35-$ & 0.21 & & & 0.32 \\
\hline $40-$ & 0.47 & & 1. 34 & \\
\hline $45-$ & 0.67 & 0.0 & & \\
\hline $50-$ & 0.82 & 10 & & 1.22 \\
\hline $55-$ & 0.82 & & 2. 12 & \\
\hline $60-$ & 0.78 & & & \\
\hline $65-$ & 0.93 & & & \\
\hline $70-$ & 1.06 & 12 & 2. 23 & \\
\hline $75-$ & 1.00 & & & \\
\hline Total & 0.09 & 0.5 & 0.74 & 0.57 \\
\hline
\end{tabular}

니다.

우리나라는 두빈쩨로 밚아서 备各 $4.2 \%$ 와 $0.74 \%$ 이 었읍니다.

\section{3. 年齡別有病率(菌陽性患者)(表 3)}

어느 나라에서나 年龄이 높을수록 菌陽性者有病率이 높지만 우리나라의 境遇 特히 20歲群 $(0.73 \%)$ 乃至 40 歲群 $(1.34 \%)$ 에서도 相當히 높은 率을 보이고있어 深刻 한 問題가 아닐수 없읍니다.

\section{4. 結核患者의 治療經歷(表 4)}

各國結核貝態調查에 나타난 結果를 보면 우리나라를 包含한 四個國 全部가 아직도 全體菌陽性患者의 治療率 이 $70 \%$ 未滿이고 韓國의 境遇 $30.3 \%$ 만이 過去에 治㷧 를 받있거나 現在 治療中인 것으로 나타났읍니다. 적어 도 治療者 未治源者의 比率이 正反對로 나타날때 까지

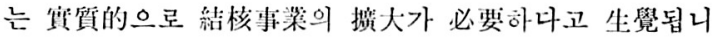
다.

Table 4. Treatment history of bact. pos. cases by national prevalence survey.

\begin{tabular}{l|c|c|c}
\hline \multirow{2}{*}{ Country } & year. & \multicolumn{2}{|c}{$\%$ of Treatment history } \\
\cline { 2 - 4 } & & No. & yes \\
\hline Japan & 1968 & 38.6 & 61.4 \\
Korea & 1970 & 69.7 & 30.3 \\
(China Taiwan) & 1967 & 74.2 & 25.8 \\
Malaysia & 1970 & 88.9 & 11.1 \\
\hline
\end{tabular}

\section{5. 治療事業(表 5)}

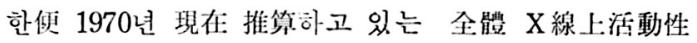
患者와 菌陽性者에 對한 治療中인 者의 차지하는 比率 은 四個國이 다 半도 못 되고 있으며 우리나라의 境遇 菌陽性者의 $39 \%$ 가 治療를 받고 있고 菌陰性인 患者의 境遇 겨우 $7 \%$ 에 지나지 않읍니다.

6. 年間新患發生率 (表 6)

우리나라와 日⽊ㅅ을 除外한 다른나라의 情報는 얻지

Table 5. Estimated coverage of TB treatment service 1970

\begin{tabular}{|c|c|c|c|c|c|}
\hline \multirow{2}{*}{ Country } & \multicolumn{2}{|c|}{ Estimated total no. } & Actual no. pts on treatment & \multicolumn{2}{|c|}{$\%$ coverage } \\
\hline & Xray Suspects & Bact. conformed & Xray Suspect Bact. conformed & Xray. & . Bact. \\
\hline Korea & $1,118,000$ & 197,000 & 78.330 & 7 & 30 \\
\hline China (Taiwan) & 260,000 & 46,000 & 19. 010 & & 41 \\
\hline Japan ${ }^{*}$ & $(1,530,000)$ & & $(724,810)$ & & $(47)$ \\
\hline Malaysia & & 28,334 & 17,000 & & 28 \\
\hline
\end{tabular}

※o separate figure is available 
결핵 및 호홉기질환 Vol. 19, No. 1, Jan., 1972

Table 6. Annual incidence of tuberculosis

\begin{tabular}{c|c|c|c}
\hline Country & Period & $\begin{array}{c}\text { Active TB } \\
\text { by Xray }\end{array}$ & $\begin{array}{c}\text { Bact. } \\
\text { conformed }\end{array}$ \\
\hline $\begin{array}{c}\text { Korea } \\
\text { longitudinal } \\
\text { survey }\end{array}$ & $1969 \sim 70$ & 0.60 & 0.33 \\
$\begin{array}{c}\text { F. U. of Nat'1 } \\
\text { prev. survey }\end{array}$ & $1970 \sim 71$ & 0.35 & 0.24 \\
Japan & $1953 \sim 54$ & 0.37 & 0.01 \\
$\prime \prime$ & $58 \sim 59$ & 0.23 & $?$ \\
$\prime \prime$ & $1963 \sim 64$ & 0.17 & 0.01 \\
\hline
\end{tabular}

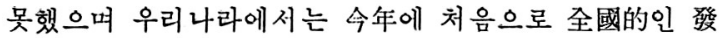
生率調查를 實施하였읍니다. 即 昨年(1970年) 全國結核 實態調查의 標本地域中 2 分之 1 에 該當하는 43 個地域에 서 滿一年만에 다시 調査를 했는데 아직 最終集計 分析 이 다 되지 못했읍니다. 따라서 여기에 내놓은 数字는 于先 急한대로 뽑아 본 것이며 境遇에 따라서는 若干 變動이 있을 수도 있다는 것을 미리 말씀드려 둡니다. 이에 依하면 X線上 活動性結核은 年間 $0.35 \%$ 로 日本 의 1953 年의 發生率 $0.37 \%$ 와 비슷하였고 菌陽性者의 新發生은 $0.24 \%$ 로 大端히 높았읍니다. 以上으로 結核 의 實態에 關한것을 大略 말씀 드리고

\section{WHO Seminar}

이번 WHO Seminar 에서 論議된 重要한 事項을 簡單 히 말씀 드리겠읍니다.

첫째 1980年까지 이 地域에서 이루어져야 할 結核管 理의 目標를 다음과 같이 하자는 것입니다. 即 (1)十大 死因中에서 結核을 몰아내고 (2)結核死亡率(全結核)을 人口 100,000 對 10 以下로 내리고 (3)叙抹陽性者의 有病 率이 $0.1 \%$ 以下라야 하겠다는 것입니다. 그런데 우리나 라의 鋈抹陽性者有病率은 1970 년에 $0.5 \%$ 로 나타났읍 니다.

다음에는 結核管理의 指針으로서 (1)疫學的으로 반드 시 소國的인 事桠이 되어야 하겠고 (2)行政的으로는 소 國의 保健組織網을 通해서 이루어져야 할 것과 (3) 技術 的으로 投資對 收獲이 考虑되야 하며 (4)社會的으로 要 望에 對한 充足이 于先 되야 하고 (5)經濟的으로 國家經 濟(財政)에 맞추어서 이루어져야 하겠다는 것입니다. 以 上 諸條件을 우리나라의 現事業에 비추어 보면 疫學的 이나 行政的인 面에서는 다른 나라들에 比해 볼때 越等 히 満足할만한 状態로서 會議의 主管者인 WHO가 이번 Seminar 를 우리나라에서 開催하게된 理由도 다른 나라 들에 보여주기 䉆한 措置라고 말하고 있읍니다. 다음
技術的이나 社會的인 面 即 投資에 對한 收獲 다시 말해 서 豫算을 投入한 만큼 患者가 줄어들었는지 또는 將來 의 展望等에 關한 評價는 아직 할 時期가 못되었다고 보며 社會的인 面 即 要望에 對한 充足을 具體的으로 말 씀하면 呼吸器症狀이 있어 도움을 바라는 사람들을 于先 治療해 주어야 한다는 理論이나 이點에 對해서는 좀더 技術的으로 改善되어야 할 餘地가 있다고 生覺합니다. 끝으로 經濟的인 面에서는 우리나라 豫算上에 保健費가 너무나 푸대접을 받고 있읍니다. 國家豫算의 $1 \%$ 밖에 안되며 結核腬算은 保健豫算의 約 $15 \%$ 程度입니다.

每人口當 美弗 約 7센트로 結核協會 豫算等을 합해도 9센트 程度인데 日本의 境遇 1弗 61센트와 比較하면 너 무나 적은 돈입니다.

다음은 技術的인 問題로 (1)BCG 接種事政에 있어서 는 되도록 빠른 時日內에 感受性人口의 $75 \%$ 以上을 按 種해야 된다는것과 (2)患者發見과 治療事業에 있어 菌 陽性患者(塗抹陽性)의 $70 \%$ 가 發見되고 治療를 받을때 까지는 陽性者治療에 注力해야 한다고 强調되었고 所謂 $100 \%$ Reginen 이라고 紹介된 强力初治療（三者每日投 藥)에 따른 完全監視下의 週二回 間헐 療法의 優秀性에 對하여 많은 實驗例를 들어 勸獎되었읍니다.

\section{III. 結核事業의 分析}

다음에 우리나라 結核事業에 關한 業績分析을 하기前 에 簡單한 歷史를 더듬어보면 1952年부터 1961年에 이 르는 十年間은 初創期的으로 集團 BCG接種 $\mathrm{X}$ 線集團 檢䧐等이 始作되었고 1962年에서 1967年에 이르는 5年 間에 各道結核检查所 設置, 保健所, 保健支所의 結核管 理要員 配置 結核管理醫師配置等 全國의 組織이 거의 完成되고 1965年에는 第一次 全國絬核賽態調查를 하는 等 눈부신 發展을 보게 되었으며 1967년부터 現在까지 는 主로 喀痰檢査에 依한 患者 發芫等 事業內容의 蜜充 과 結核研究院의 設立이 있었고 結核研究院에서는 第二 次 全國結核實態調查, 保健所事業評價調査, 新患發生率 調查等 重要한 疫學的인 調査를 하였고, 今年에는 國際 會議에도 큰 役割을 한 바 있읍니다.

다음은 1970年度 우리나라 結核事業의 業績分析입니 다.

첫째 $\mathrm{BCG}$ 接種事業(表 7)에 있어 就學兒童 全國民學 校新入生의 $95 \%$ 內外를 Tuberculin 反應하여 $83.3 \%$ 에 對해 $\mathrm{BCG}$ 接種을 完了暗고 未就學兒童人口의 $36.9 \%$ 를 Tuberculin 反應距이 直接接種 했읍너다. 
Table 7. Achievement of TB control 1970 1. BCG Vaccination

\begin{tabular}{l|c|c}
\hline & School ent. & Preschool (0-5Y) \\
\hline T. tested & $95.0 \% \pm$ & (direct BCG) \\
Vaccinated & $83.3 \%$ & $36.9 \%$ \\
Prev, covered & $50.0 \% \pm$ & $38.9 \%$ \\
\hline
\end{tabular}

BCG 接種의 質的管理를 編해 50 俆回의 評價陚驗을 中央 및 各市道에서 實施 했는데 그 結梁는 Post Vaccination Tuberculin alergy 의 平均值가 $10 \mathrm{~mm}$ 末溯 인 境遇가 相當히 많았읍니다. 이것은 소버⿺ 1500 名 以 上의 邑面要員들의 訓練不足等에서 오는것이 아닌가 生 學됩니다.

患者發見事業(表, 8)에 있어서는 年間 喀痰檢查에 依 해 18,279 名의 陽性患者를 發見했고 이는 人口 1000 名 賞 0.63 에 該當됩니다 한便 推算되는 全國陽性患者數 의 $9.0 \%$ 에 該當되머 要員 1 名이 年間 10.9 名을 發見㢺 고 소體检查件數의 $1.9 \%$ 이었읍니다. 여기에서 問題되 는것은 檢查件數에 對한 發見率이 낮다는 것입니다. 可 檢物의 性質에 따라 相當한 差界가 있으니 要員들의 헛 手苦를 덜기 爲하여 좀더 可檢物 乃至는 對象者의 選定 에 倛重해야 되겠다는 것입니다.

Table 8. Achievement of TB Control 1970 (2-1.) Case finding by Sputum

\begin{tabular}{lc}
\hline number detected & 18,279 \\
per 1, 000 pop & 0.63 \\
$\%$ to total estimated & 9.0 \\
detected per worker & 10.9 \\
$\%$ to examined & 1.9 \\
\hline
\end{tabular}

$\mathrm{X}$ 線憸查(表 9)에 依한 患者發見에 있어서는 年間 65,841 名을 發見䪭는데 소體撮影者數의 $7.1 \%$ 이었고 人 口 1,000名當 0.23 名侸인 同時에 全推算患者數의 $5.6 \%$ 에 該當되고 이中에 菌陽性患者와 空洞性患者를 包含하 여 所謂 傅染性患者가 約 $20 \%$ 程度이었읍니다.

Table 9. Achievement of TB Control 1970 (2-2.) Case finding by Xray.

$\begin{array}{lc}\text { number detected } & 65,841 \\ \% \text { to examined } & 7.1 \\ \text { per } 1,000 \text { population } & 0.23 \\ \% \text { to total estimated } & 5.6 \\ \begin{array}{l}\% \text { infectious } \\ \text { sput }(+) \text {, cavitary. }\end{array} & 20.0\end{array}$

결핵 및 호홉기질환 Vol. 19, No. 1, Jan., 1972

다음 治療事業(表 10)에 있어 年間 새로 登錄된 菌陽 性患者가 人口 1,000名當 1.07 名이었는데 喀疢檢査에서 發見된 患者와 X 線으로 發見된 患者가 各各 $0.57,0.50$ 으로 거의 同數이었으며 소. 體推定患者數의 $15.3 \%$ 에 該 當합니다. 1970年末 現在 登錄狀況을 보면 總登錄患者,

Table 10. Achievement of TB control 1970 (3.) Treatment

Total Registered infectious

$\begin{array}{ll}\text { per } 1,000 \text { pop. } & 1.07 \\ \text { by Sput } & 0.57 \\ \text { br Xray } & 0.50 \\ \% \text { to total estimated } & 15.3\end{array}$

AT THE END OF 1970

Total patient on treatment

171,362

$\%$ of infectious cases

46.9

per 1, 000 population

5.88

$\%$ to total estimated

14.4

治療中인 患者가 171,362 名이었고 이中 菌陽性患者가 $46.9 \%$ 이었고 소體患者는 人口 1,000 名當 5.88 名에 該 當되는 同時 全體 推定患者數의 $14.4 \%$ 에 不過하였읍니 다.

다음은 이들 患者에게 投藥된 處方別로(表 11) 1969年, 1970年 1971年을 比較해보면 큰 差異는 없으나 INH+SM 과 INH+PAS 群이 若干 坦加된 反面 Thiacetazane+ INH 群은 顯著히 減少되었고 三者併合群(INH+PAS+ $\mathrm{SM}$ )이 相當히 坦加되어 相當한 進展을 볼수 있었읍니

Table 11. Drug Regimen prescribed at H.C. $\%$ to Total Pts.

\begin{tabular}{|c|c|c|c|c|}
\hline & $\begin{array}{l}1969 \\
\text { (Oct) }\end{array}$ & $\begin{array}{c}1970 \\
(\mathrm{Oct})\end{array}$ & $\begin{array}{l}1971 \\
\text { (Jul) }\end{array}$ & $\begin{array}{l}\text { Supply } \\
1971\end{array}$ \\
\hline INH alone & 45.2 & 50.0 & $\begin{array}{c}49.2 \\
(69,870)\end{array}$ & 50.0 \\
\hline $\mathrm{INH}+\mathrm{SM}$ & 25.9 & 26.5 & $\begin{array}{c}27.9 \\
(39,639)\end{array}$ & 35.0 \\
\hline $\mathrm{INH}+\mathrm{PAS}$ & 9.9 & 11.4 & $\begin{array}{l}12.4 \\
(17,562)\end{array}$ & 10.0 \\
\hline $\mathrm{TH}-\mathrm{I}$ & 10.4 & 5.3 & $\begin{array}{l}2.1 \\
(2,918)\end{array}$ & \\
\hline $\mathrm{TH}-\mathrm{I}+\mathrm{SM}$ & 7.1 & 5.0 & $\begin{array}{c}5.0 \\
(7,106)\end{array}$ & 5.0 \\
\hline $\mathrm{INH}+\mathrm{SM}+\mathrm{PAS}$ & 1.5 & 1.8 & $\begin{array}{l}3.5 \\
(4,924)\end{array}$ & \\
\hline Intermittent & - & 0.03 & $?$ & \\
\hline Total & 100.0 & 100.0 & $\begin{array}{c}100.0 \\
(142,019)\end{array}$ & \\
\hline
\end{tabular}


다. 다만 INH 單獨治療群이 계속 $50 \%$ 線을 維持하고 있 는데 이것은 所謂 chronic case 로 併合療法을 一年 또 는 그 以上 계속해도 菌陰轉이 안된 患者가 늘어가고 있는 實情이며 輕症菌陰性患者는 原則的으로 治療對象 에서 除外하기로 되어 있으나 아직도 많은 患者가 INH 單獨治療를 받고있는 實情입니다. 이런것은 하루 速히 完全히 是正되어야 하겠으며 어떤 境遇에는 保健所에서 藥品補給 받는 比率에 맞추어·處方을 左右하는 수가 없 지 않은것 같읍니다. 이런 것도 勿論 었어서는 안될일입 니다. 以上은 소國保健所를 通해 筫施된 業績이었고 다 음에 몇가지 調査結蝀로 事業成果에 對한 疫學的인 評 價를 시도해 보았읍니다. (表 12)

Table 12. Bacteriological follow up of 1,558 patients randomly sampled from H.C.s. 1971

\begin{tabular}{|c|c|c|c|c|c|}
\hline & \multicolumn{2}{|c|}{ Sputum cultured } & \multicolumn{3}{|c|}{ Sensitivity tested } \\
\hline & Total & positive & Total & sensit. & resist. \\
\hline No. & 1,367 & 294 & 237 & 24 & 213 \\
\hline$\%$ & 100,0 & 21.5 & 100.0 & 10.1 & 89.9 \\
\hline
\end{tabular}

Resistant to

\begin{tabular}{l|r|r|r|r|r}
\hline & INH & PAS & SM & $\begin{array}{c}2 \text { drugs } \\
\text { includ. } \\
\text { INH }\end{array}$ & 3 drugs \\
\hline $\begin{array}{l}\text { No. } \\
\% \\
\text { to total } \\
\text { tested }\end{array}$ & 86.1 & 49.0 & 60.3 & 33.3 & 35.0 \\
\hline
\end{tabular}

\section{IV. 結核事業의 疫學的評價}

現在 保健所에서 治療叶인 患者 1,558 名을 無作爲로 選出하여 이中喀痰檢査를 할수 있었던 사람이 1,367名, 그中에 菌陽性으로 나타난것이 294名으로 $21.5 \%$ 이었읍 니다. 다시 말하면 登錄當時 約 $50 \%$ 가 陽性이었으누 調查當時 約 $2 / 3$ 의 患者가 6個月以上 治療를 받고 있었 으며 소體的으로 陽性患者의 數가 $20 \%$ 線으로 줄었다는 것은 나머지 $30 \%$ 는 陰轉되었고 $20 \%$ 는 陰轉될 期會가 極히 적은것으로 推測되는 것입니다. 그 證據로 이사람 들의 感愛性檢査를 해본 結果 $86.1 \%$ 가 $\mathrm{INH}$ 에 酎性이 었고 소體的으로 $89.9 \%$ 가 INH 또는 SM. PAS 어느 한가지 또는 두가지 以上에 耐性이었읍니다. 한 佽 疢陽 性患者의 運命을 調查한 여러個의 調查結果를 比較해보 면(表 13) 1966年度에 登錄되었고 3個年을 계속 치료中 인 患者 143 名에 對한 菌陰轉率이 겨우 $44.1 \%$ 에 지나
지 못했고 1967年 1968年度 患者는 治療 1年半 乃至二 年에 $52.1 \%, 54.0 \%$ 로 若干 改善되었고 1970年 全國實 態調査時에 發胃된 患者 95名을 滿一年後 調查한 結果 $67.4 \%$ 로 相當히 向上되었다고 生覺합니다. 秉해서 死 亡者도 1966年度에 $11.2 \%$ 이었는데 1970年度에는 $5.3 \%$ 로 나타났읍니다. 이것은 Frimod M $\phi 1 l e r$ 가 南印度에서

Table 13. Observation on Fate of sputum positive cases

\begin{tabular}{|c|c|c|c|c|}
\hline Cohort of pts & $\begin{array}{l}\text { No. of } \\
\text { pts }\end{array}$ & $\begin{array}{l}\text { after } \\
\text { admis- } \\
\text { sion in } \\
\text { months }\end{array}$ & $\begin{array}{c}\% \\
\text { Sput co- } \\
\text { nverted }\end{array}$ & Dead \\
\hline $19662 \mathrm{HCs}$ & 143 & 36 & 44.1 & 11.2 \\
\hline $196729 \mathrm{HCs}$ & 652 & $12-18$ & 52.1 & $?$ \\
\hline 1968 32HCs & 570 & $12-18$ & 54.0 & $?$ \\
\hline $\begin{array}{r}1968-696 \mathrm{HCs} \\
2 \text { clinics }\end{array}$ & 628 & $24-48$ & 70.4 & 6.8 \\
\hline $\begin{array}{c}1970 \begin{array}{c}\text { Prevalence } \\
\text { survey }\end{array}\end{array}$ & 95 & 12 & 67.4 & 5.3 \\
\hline $\begin{array}{c}* 1964 \text { South } \\
\text { India }\end{array}$ & 123 & 12 & 64.0 & 10.0 \\
\hline
\end{tabular}

調査한 INH 感性이었던 患者 123 名의 運命에 關한 結果 보다 若干 좋은 便이기도 합니다. (우리나라의 境遇 治 療前 初回酎性患者도 있었을 것이라고 본다면)

Table 14. Comparison of reduction of prevalences between results of routain service and control

\begin{tabular}{l|r|r|r|r|r}
\hline \multicolumn{1}{c|}{ Year } & MIN & MA & FA & Total & $\begin{array}{l}\text { survey } \\
\text { pop. }\end{array}$ \\
\hline 1965 & 3.3 & 1.2 & 0.6 & 5.1 & 13,438 \\
1970 & 2.9 & 0.9 & 0.4 & 4.2 & $18 ; 264$ \\
Reduction rate & $\frac{12.1}{25.0}$ & $\frac{33.3}{1.7}$ & $\frac{17.7}{1}$ & \\
1971 & 1.5 & 0.2 & 1.8 & 8,931 \\
Reduction rate & $\frac{62.1}{-}$ & 44.4 & 50.0 & 57.1 & \\
\hline
\end{tabular}

1965 \& 1970 Random sample of whole country

1971 Follow up of the sample of 1970 one year after treatment given

다음은 1965年에서 1970年에 이르는 5個年間에 全國 的으로 患者가 減少된 率과 1970年 全國實態調査한 地 域內에서 一年後에 다시 調查한 結果 減少된 率을 比較 한 것인데(表 14 ) 前者는 $5.1 \%$ 에서 $4.2 \%$ 로 $17.7 \%$ 의 減少率이었고 後者는 $4.2 \%$ 에서 $1.8 \%$ 로 $57.1 \%$ 라는 顯 
著한 減少率을 볼수 있읍니다. 이것은 當然한. 結果라고 볼수 있는 것입니다. 即 後者의 境遇 그 地域內의 모든 住民을 檢䛦한 結果 모든 患者가 發見되어 治䝤를 받도

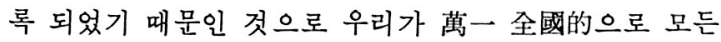
住民이、每年 检䧐些 받을 수 있다면 相當히 빠른 速度 로 結核을 退治할수 있다는 증거도 되지 않을가 합니 다.

끝으로 絬論을 짓기 営하여 參考로 우리나라 結核事 業에 從事하고 있는 要員의 動態를 말씀드리면(表 15)

Table 15. Number of full time workers for TB control

\begin{tabular}{r|r|r|r|r|r}
\hline & Central & $\begin{array}{c}\text { Provin- } \\
\text { (cial) }\end{array}$ & $\begin{array}{c}\text { County } \\
\text { (Gun) }\end{array}$ & $\begin{array}{c}\text { Town } \\
\text { Myon }\end{array}$ & Total \\
\hline 1963 & 18 & 31 & & & 49 \\
1964 & 18 & 61 & 189 & & 268 \\
1966 & 18 & 85 & 189 & & 292 \\
1967 & 18 & 85 & 189 & 1,334 & 1,629 \\
1970 & 14 & 44 & 482 & L, 473 & 2,013 \\
\hline
\end{tabular}

\begin{tabular}{lcc}
\hline & GOV. & KNTA \\
MD & 11 & 6 \\
PHN & 24 & - \\
LAB & ${ }^{1}(282)$ & ${ }^{2}(25) 50$ \\
XRY & ${ }^{1}(192)$ & ${ }^{2}(18) 55$ \\
AID. N & 1673 & \\
$*^{1}(\mathrm{C}$ & ) majority are not well qualified. \\
${ }^{2}(\mathrm{C}$ & ) well qualified.
\end{tabular}

1963年에 中央과 道를 合하여 모두 49名이 있었고 1964 年 保健所에 管理要員을 配定함으로서 268名으로 늘었 고 1967年에는 邑面要員을 配置 하므로서 1,629名 1970 年 現在 洞要員等을 包含 2,013 名으로 늘어 났읍니다만 醫師 看護員等 專門技術者는 아직도 不足하고 大部分이 補助看護員들 입니다.

\section{V. 問 題 點}

以上 말씀드린 實情을 土音로 몇가지 問題點을 간추 려 보면 첫째 行政的으로는 政府豫算이 于先 㫮額되어
야 하겠다는 것입니다. 藥品費가 不足하고 要員의 處遇 를 改善해서 優秀한 要員을 確保해야 하겠읍니다. 그러

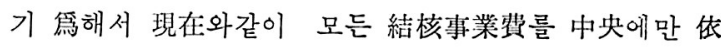
存하지 말고 地方費에서 分擔해야 한다고 生覺합니다. 組織面에서 保健所를 市道值轄로 하는것이 保健所長의 意㥕과 责任感을 더 가지게 할 것입니다. 現在로는 保健 所末端職員의 人事檴도 郡守손에 단렷기 때문에 人事管 理도 事業과는 동멸어진 方向으로 하고 있는 것이 非一非 再인 貫情입니다. 또 巾道에 結核保가 新設 되어야 하 겠읍니다. 現在로서는 너무나 行政이 微弱해서 一線의 指湆監督이 소홀합니다. 다음 現在 結核協會가 運營中 인 i道絬核检查所와 移動檢獄㤠을 早速히 政府가 引 受해 줄것을 勸하고 싶습니다. 애냐하면 結核協會의 豫

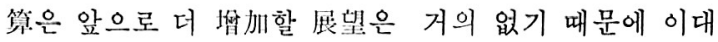
로 나간다면 協會가 繼續해야 할 啓蒙指導事業, 調查研 究事奖乃至는 要員訓練事業이 菱縮臣 念虑가 큽니다. 다음은 抗結核制의 自由肘賣를 禁止해야 합니다. 現在 대로 버려두면 一次樂은 㚲捨하고 二次組에도 耐性이 많 이 생겨 問題거리가 안될 수 없읍니다. 또 한가지 一般 開業醫師给 積極協助가 要望됩니다. 例를 들어 治療하 던 患者가 治療를 中斷就을 境遇 保健所와 連絡해서 follow up 할 수 있는 制度的 措置가 必要하고 距離關 係로 保健所에 가기가 어려운 極貧患者에 對한 便宜도 보아주어야 할 것입니다.

다음은 純全히 技術的인 問題입니다만 BCG 接種事羖 예 있어서는 末就學兒童의 接種率을 올리는 方法과 接 種技術向上:에 经力해야하며 患者發見事哭에 있어서는

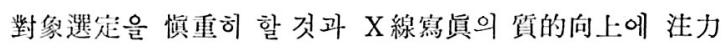
하고 喀痰检查能力도 向上되어야 하겠읍니다. 治療事栄 에 關해서 難治患者에 對한 對策을 趼究해야 하겠고 强

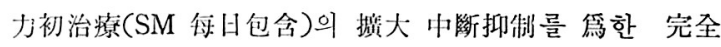
監視下 治療等이 重要합니다.

끝으로 䠓師와 患者의 人間關係維帶를 積極 要望합니 다. 保健所長을 包含한 結核事榮에 從事하는 모든 醫師 는 臬摸患者를 捽하는 時間이 너무나 적다고 生學됩 니다. 